\title{
Author Correction: Arsenic mobilization by anaerobic iron-dependent methane oxidation
}

\author{
Martyna Glodowska, Emiliano Stopelli, Magnus Schneider, Bhasker Rathi, Daniel Straub (D), Alex Lightfoot, \\ Rolf Kipfer, Michael Berg (D), Mike Jetten, Sara Kleindienst (1D, Andreas Kappler (1) \& AdvectAs Team Members*
}

Correction to: Communications Earth \& Environment https://doi.org/10.1038/s43247-020-00037-y, published online 12 November 2020.

The original version of this Article contained an error in the Acknowledgements, where a sentence incorrectly ended with 'for the help with XANES mesures'.

In the correct version, this has been replaced with 'for having collected and analyzed XANES data at the As K-edge reported in Supplementary Figure 3'.

The issue has been corrected in both the PDF and HTML versions of the Article.

The original version of the Supplementary Information associated with this Article contained an error in the caption of Supplementary Figure 3, where information was omitted at the end of the caption. The correct version adds 'Linear combination fits (LCF) (red curves) of experimental data for the studied samples (black curves) were performed using the set of reference compound spectra As (V)- and As(III)-sorbed ferrihydrite reported in Wang et al. $2018^{1}$. The LCF analysis procedure applied here is detailed in Resongles et al. 2016 ${ }^{2}$. Arsenic K-edge XANES data of the samples have been collected in fluorescence detection mode using 100 elements Ge Canberra(TM) detector at liq. N2 temperature on the 11-2 wiggler beamline of Stanford Synchrotron Radiation Lightsource (SSRL). Use of the SSRL, SLAC National Accelerator Laboratory, is supported by the U.S. Department of Energy, Office of Science, Office of Basic Energy Sciences under Contract DE-AC02-76SF00515.' after 'unknown'. Supplementary References 1 and 2 were added and the Supplementary References renumbered accordingly.

The HTML has been updated to include a corrected version of the Supplementary Information.

Published online: 16 December 2020

\author{
Additional information \\ Supplementary information is available for this paper at https://doi.org/10.1038/s43247-020-00068-5.
}

\footnotetext{
(i) Open Access This article is licensed under a Creative Commons Attribution 4.0 International License, which permits use, sharing, adaptation, distribution and reproduction in any medium or format, as long as you give appropriate credit to the original author(s) and the source, provide a link to the Creative Commons license, and indicate if changes were made. The images or other third party material in this article are included in the article's Creative Commons license, unless indicated otherwise in a credit line to the material. If material is not included in the article's Creative Commons license and your intended use is not permitted by statutory regulation or exceeds the permitted use, you will need to obtain permission directly from the copyright holder. To view a copy of this license, visit http://creativecommons.org/licenses/by/4.0/.
}

(c) The Author(s) 2020 